\title{
ON THE MATHEMATICAL FOUNDATIONS OF MACBETH
}

by

\section{Carlos A. Bana e Costa ${ }^{1,2}$, Jean-Marie De Corte ${ }^{3}$ and Jean-Claude Vansnick ${ }^{3}$}

${ }^{1}$ Centre for Management Studies of Instituto Superior Técnico, Technical University of Lisbon, Av. Rovisco Pais, 1049-001 Lisbon, Portugal

${ }^{2}$ Department of Operational Research, London School of Economics and Political Science, Houghton Street, London WC2A 2AE, U.K. (c.bana@Ise.ac.uk)

${ }^{3}$ Centre de Recherche Warocqué, Université de Mons-Hainaut, Place du Parc, 20, 7000 Mons, Belgium 
First published in Great Britain in 2004

by the Department of Operational Research

London School of Economics and Political Science

Copyright (C) The London School of Economics and Political Science, 2004

The contributors have asserted their moral rights.

All rights reserved. No part of this publication may be reproduced, stored in a retrieval system, or transmitted in any form or by any means, without the prior permission in writing of the publisher, nor be circulated in any form of binding or cover other than that in which it is published.

Typeset, printed and bound by:

The London School of Economics and Political Science Houghton Street

London WC2A 2A 


\title{
ON THE MATHEMATICAL FOUNDATIONS OF MACBETH
}

\author{
Carlos A. Bana e Costa ${ }^{1,2}$, Jean-Marie De Corte ${ }^{3}$, Jean-Claude Vansnick ${ }^{3}$ \\ ${ }^{1}$ Centre for Management Studies of Instituto Superior Técnico, Technical University of Lisbon \\ Av. Rovisco Pais, 1049-001 Lisbon, Portugal (carlosbana@netcabo.pt) \\ 2 Department of Operational Research, London School of Economics \\ Houghton Street, London WC2A 2AE, U.K. (c.bana@Ise.ac.uk) \\ ${ }^{3}$ Centre de Recherche Warocqué, Université de Mons-Hainaut \\ Place du Parc, 20, 7000 Mons, Belgium (DeCorte@umh.ac.be / Vansnick@umh.ac.be)
}

\begin{abstract}
MACBETH (Measuring Attractiveness by a Categorical Based Evaluation Technique) is a multicriteria decision analysis approach that requires only qualitative judgements about differences of value to help an individual or a group quantify the relative attractiveness of options. We present an up-to-date survey of the mathematical foundations of MACBETH. Reference is also made to real-world applications and an extensive bibliography, spanning back to the early 1990's, is provided.
\end{abstract}

Keywords: MACBETH, questioning procedure, qualitative judgements, judgmental, inconsistency, cardinal value measurement, interaction. 


\section{Introduction}

Let $X$ (with $\# X=n \geq 2$ ) be a finite set of elements (alternatives, choice options, courses of action) that an individual or a group, $J$, wants to compare in terms of their relative attractiveness (desirability, value).

Ordinal value scales (defined on $X$ ) are quantitative representations of preferences that reflect, numerically, the order of attractiveness of the elements of $X$ for $J$. The construction of an ordinal value scale is a straightforward process, provided that $J$ is able to rank the elements of $X$ by order of attractiveness - either directly or through pairwise comparisons of the elements to determine their relative attractiveness. Once the ranking is defined, one needs only to assign a real number $v(x)$ to each element $x$ of $X$, in such a way that:

$1 v(x)=v(y)$ if and only if $J$ judges the elements $x$ and $y$ to be equally attractive;

$2 v(x)>v(y)$ if and only if $J$ judges $x$ to be more attractive than $y$.

The problem, however, is that, in a multiple criteria decision analysis, conclusions based on a additive value model may be quantitatively meaningless, because "to be quantitatively meaningful a statement should be unaffected by admissible transformations of all the quantities involved." [53, p. 91]. A necessary condition is that each value scale should be unique up to a positive affine transformation (an interval scale), as it is with a value difference scale. A value difference scale (defined on $X$ ) is a quantitative representation of preferences that is used to reflect, not only the order of attractiveness of the elements of $X$ for $J$, but also the differences of their relative attractiveness, or in other words, the strength of $J$ 's preferences for one element over another. Unfortunately, the construction of an interval value scale is usually a difficult task.

Both numerical and non-numerical techniques have been proposed and used to build a value difference scale (hereafter, simply called a value scale) - see [51] for a survey. Examples of numerical techniques are direct rating and difference methods - see descriptions in [61, 62] and [41]. They require $J$ to be able to produce, either directly or indirectly, numerical representations of his or her strengths of preferences, which is not a natural cognitive task. Non-numerical techniques, such as the bisection method (also described by the same authors), are based on indifference judgements, forcing $J$ to compare his or her strengths of preferences between two pairs of elements of $X$, therefore involving at least three different elements in each judgement. This requires $J$ to perform an intensive cognitive task and is prone to be substantively meaningless - "substantive meaningfulness (...) requires that the qualitative rela- 
tions (...) being modelled should be unambiguously understood by the decision maker." [53, p. 91].

The aforementioned difficulties inspired the development of MACBETH "Measuring Attractiveness by a Categorical Based Evaluation Technique". The original research on the MACBETH approach was carried out in the early 1990's - see $[2,29]$ and [35] - as a response to the following question:

How can a value scale be built on $X$, both in a qualitatively and quantitatively meaningful way, without forcing $J$ to produce direct numerical representations of preferences and involving only two elements of $X$ for each judgement required from $J$ ?

Using MACBETH, $J$ is asked to provide preferential information about two elements of $X$ at a time, firstly by giving a judgement as to their relative attractiveness (ordinal judgement) and secondly, if the two elements are not deemed to be equally attractive, by expressing a qualitative judgement about the difference of attractiveness between the most attractive of the two elements and the other. Moreover, to ease the judgemental process, six semantic categories of difference of attractiveness, "very weak", "weak", "moderate", "strong", "very strong" or "extreme", or a succession of these (in case hesitation or disagreement arises) are offered to $J$ as possible answers. This is somewhat in line with similar ideas previously proposed by Saaty [59] in a ratio measurement framework, or by Freeling [52] and Belton [40] in difference value measurement. By pairwise comparing the elements of $X$ a matrix of qualitative judgements is filled in, with either only a few pairs of elements, or with all of them (in which case $n \cdot(n-1) / 2$ comparisons would be made by $J$ ).

A brief review of the previous research on MACBETH is offered in Section 2, together with the evolution of its software's development. It shows that, on a technical level, MACBETH has evolved through the course of theoretical research and also through its extension to the multicriteria value measurement framework in numerous practical applications (see Section 10). Its essential characteristics, however, have never changed.

Sections 3 through 9 of this chapter present an up-to-date survey of the mathematical foundations of MACBETH. Section 3 describes the two MACBETH modes of questioning mentioned above (both involving only two elements at a time) used to acquire preferential information from $J$, as well as the types of information that can be deduced from each of them. The subsequent sections are devoted to an up-to-date rigorous survey of the mathematical foundations of MACBETH. Section 4 addresses the numerical representation of those different types of 
information. These numerical representations are only possible if $J$ 's responses satisfy certain rational working hypotheses. Section 5 deals with the "consistency / inconsistency" of the preferential information gathered from $J$ and Section 6 explores the practical problem of testing the consistency of preferential information. How should an inconsistency be dealt with? The answer to this question is the subject of Section 7 . Sections 8 and 9 present what MACBETH proposes to $J$ once the preference information provided by $J$ is consistent. Finally, Section 10 lists several real-world applications of multicriteria value analysis in which the MACBETH approach was used.

- $J$ is an evaluator, either a individual or group.

- $X$ (with $\# X=n \geq 2$ ) is a finite set of elements (alternatives, choice options, courses of action) that $J$ wants to compare in terms of their relative attractiveness (desirability, value).

- $\Delta a t t(x, y)$ is the "difference of attractiveness between $x$ and $y$ for $J$ ", where $x$ and $y$ are elements of $X$ such that $x$ is more attractive than $y$ for $J$.

- $\Delta \operatorname{att}(x, y) \succ \Delta a t t(z, w)$ means that $\Delta a t t(x, y)$ is greater than $\Delta a t t(z, w)$.

- $\phi$ is an empty set.

- $\mathbb{R}$ is the set of real numbers.

- $\mathbb{R}_{+}=\{x \in \mathbb{R} \mid x \geq 0\}$.

- $\mathbb{R}^{*}=\mathbb{R} \backslash\{0\}$.

- $\mathbb{R}_{+}^{*}=\mathbb{R}_{+} \backslash\{0\}$.

- $\mathbb{Z}$ is the set of integer numbers.

- $\mathbb{N}$ is the set of non-negative integer numbers.

- $\mathbb{N}^{*}=\mathbb{N} \backslash\{0\}$.

- $\mathbb{N}_{s, t}=\{s, s+1, \ldots, t\}=\{x \in \mathbb{N} \mid s \leq x \leq t\}$ where $s, t \in$ $\mathbb{N}$, and $s<t$.

- The transpose of a matrix $A$ will be denoted by ${ }^{t} A$. 


\section{Previous Research and Software Evolution}

In order to build an interval (value) scale based on the qualitative judgements of difference of attractiveness formulated by $J$, it is necessary that the six MACBETH categories "very weak", "weak", "moderate", "strong", "very strong" or "extreme" be represented by non-overlapping (disjoint) intervals of real numbers. The basic idea underlying the initial development of MACBETH was that the limits of these intervals should not be arbitrarily fixed a priori, but determined simultaneously with numerical value scores for the elements of $X$. Research was then conducted on how to test for the existence of such intervals and how to propose numerical values for the elements of $X$ and for the limits of the intervals - see [2, Chapter IV]. This gave rise to the formulation of a chain of four linear programs - see [31, 29, 30] and [32] - that, implemented in GAMS, were used in the first real-world applications of MACBETH as a decision aiding tool to derive value scores and criteria weights in the framework of an additive aggregation model - see [42, 43, 35] and [37]. Theoretical research conducted at the same time, and first presented in 1994 at the 11th International Conference on MCDM, demonstrated the equivalence of the approach by constant thresholds and the approach by measurement conditions - see [36].

The first MACBETH software was developed in 1994. In it, the objective function used in the GAMS implementation to determine a value scale was modified, on the basis of a simple principle - see [37] and [38]

- that makes it possible, for simple cases, to determine the scale "by hand" [34]. However, complete procedures to address and manage all cases of inconsistency were not available at that time. Therefore, the software offered its users the possibility of obtaining a compromise scale in the case of inconsistency. This initial software was used in several real world applications - see, for example, [19, 21, 23, 24, 32, 39] and [48]. However, it had several important limitations:

1 The determination of suggestions was still heuristic and did not guarantee the minimal number of changes necessary to achieve consistency;

2 It was not possible for the evaluator to hesitate between several semantic categories when expressing judgements. It, therefore, did not enable one to facilitate the management of group judgemental disagreements;

3 It forced the evaluator to first provide all of the judgements before it could run any procedure. Consequently, judgemental inconsistency could only be detected for a full matrix of judgements. As a 
result, suggestions of changes to resolve inconsistency could only then be discussed, a restriction that did not lend itself to good interaction.

Subsequent theoretical research was therefore concentrated on resolving these problems. Results reported in [46] and [56], allowing inconsistencies to be dealt with in a mathematically sound manner, were the turning point in the search for a more interactive formulation. Indeed, it was then possible to implement a procedure that automatically detects "inconsistency", even for an incomplete matrix of judgements, in a new software called M-MACBETH - see www.m-macbeth.com and [16] - which has been used to produce some of the figures in this paper. The objective of abandoning the suggestion of a compromise scale could also finally be achieved, since the origin of the inconsistency could now be found (detection of elementary incompatible systems) and explained to $J$. M-MACBETH finds the minimal number of necessary changes and, for any number of changes not greater than five, suggests all of the possible ways in which the inconsistency can be resolved. Furthermore, it is able to provide suggestions of multiple category changes, where a " $k$ categories change" is considered to be equivalent to $k$ " 1 category changes".

Real-world applications in the specific context of bid evaluation (see references in Section 10) inspired research regarding the concepts of "robustness" [46] and sensitivity [9], the results of which were then included in the software, together with the possibility of addressing potential imprecision (uncertainty) associated with impacts of options, incorporating reference levels for one criterion at any time, and graphically representing comparisons of options on any two groups of criteria. These issues are out of the scope of the present chapter and they are not also included in the version of the software, limited to scoring and weighting, embedded into the HIVIEW3 software in 2003 - see [45] and www . catalyze.co.uk.

\section{Types of Preferential Information}

\subsection{Type 1 Information}

Type 1 information refers to preferential information obtained from $J$ by means of Questioning Procedure 1.

Let $x$ and $y$ be two different elements of $X$.

Questioning Procedure 1 A first question (Q1) is asked of $J$ :

Q1: Is one of the two elements more attractive than the other?

$J$ 's response (R1) can be: "Yes", or "No", or "I don't know".

If $R 1=$ "Yes", a second question (Q2) is asked: 
Q2: Which of the two elements is the most attractive?

The responses to Questioning Procedure 1 for several pairs of elements of $X$ enable the construction of three binary relations on $X$ :

$$
\begin{aligned}
P= & \{(x, y) \in X \times X: x \text { is more attractive than } y\} \\
I=\{ & (x, y) \in X \times X: x \text { is not more attractive than } y \text { and } y \text { is not } \\
& \text { more attractive than } x, \text { or } x=y\} \\
?= & \{(x, y) \in X \times X: x \text { and } y \text { are not comparable in terms of their } \\
& \text { attractiveness }\} .
\end{aligned}
$$

$P$ is asymmetric, $I$ is reflexive and symmetric, and ? is irreflexive and symmetric. Note that $?=X \times X \backslash\left(I \cup P \cup P^{-1}\right)$, with $P^{-1}=\{(x, y) \in$ $X \times X \mid y P x\}$.

Definition 1 Type 1 information about $X$ is a structure $\{P, I, ?\}$ where $P, I$ and ? are disjoint relations on $X, P$ is asymmetric, $I$ is reflexive and symmetric, and $?=X \times X \backslash\left(I \cup P \cup P^{-1}\right)$.

\subsection{Type $1+2$ Information}

Suppose that type 1 information $\{P, I, ?\}$ about $X$ is available.

Questioning Procedure 2 The following question (Q3) is asked, for all $(x, y) \in P$ :

Q3: How do you judge the difference of attractiveness between $x$ and $y$ ?

$J$ 's response (R3) would be provided in the form " $d_{s}$ " (where $d_{1}, d_{2}$, $\ldots, d_{Q}(Q \in \mathbb{N} \backslash\{0,1\})$ are semantic categories of difference of attractiveness defined so that, if $i<j$, the difference of attractiveness $d_{i}$ is weaker than the difference of attractiveness $d_{j}$ ) or in the more general form (possibility of hesitation) " $d_{s}$ to $d_{t}$ ", with $s \leq t$ (the response "I don't know" is assimilated to the response " $d_{1}$ to $d_{Q}$ ").

Remark 1 When $Q=6$ and $d_{1}=$ very weak, $d_{2}=$ weak, $d_{3}=$ moderate, $d_{4}=$ strong, $d_{5}=$ very strong, $d_{6}=$ extreme, Questioning Procedure 2 is the mode of interaction used in the MACBETH approach and its M-MACBETH software.

R3 responses give rise to relations $C_{s t}(s, t \in \mathbb{N}, 1 \leq s \leq t \leq Q)$ where $C_{s t}=\left\{(x, y) \in P \mid \Delta_{a t t}(x, y)\right.$ is " $d_{s}$ to $d_{t}$ " $\}$. They enable the construction of an asymmetric relation on $P:\{((x, y),(z, w)) \in P \times$ $P \mid \exists i, j, s, t \in \mathbb{N}$ with $\left.1 \leq i \leq j<s \leq t \leq Q,(x, y) \in C_{s t},(z, w) \in C_{i j}\right\}$. Hereafter, $C_{s s}$ will simply be referred to as $C_{s}$. 
Definition 2 Type 1+2 information about $X$ is a structure $\left\{P, I, ?, P^{e}\right\}$ where $\{P, I, ?\}$ is type 1 information about $X$ and $P^{e}$ is an asymmetric relation on $P$, the meaning of which is " $(x, y) P^{e}(z, w)$ when $\Delta_{\text {att }}(x, y) \succ$ $\Delta_{\text {att }}(z, w) "$.

\section{Numerical Representation of the Preferential Information}

\subsection{Type 1 Scale}

Suppose that type 1 information $\{P, I, ?\}$ about $X$ is available.

Definition 3 A type 1 scale on $X$ relative to $\{P, I\}$ is a function $\mu$ : $X \rightarrow \mathbb{R}$ satisfying Condition 1 .

Condition $1 \forall x, y \in X,[x P y \Rightarrow \mu(x)>\mu(y)]$ and $[x I y \Rightarrow \mu(x)=$ $\mu(y)]$.

Let $S c_{1}(X, P, I)=\{\mu: X \rightarrow \mathbb{R} \mid \mu$ is a type 1 scale on $X$ relative to $\{P, I\}\}$. When $X, P$ and $I$ are well determined, $S c_{1}(X, P, I)$ will be noted $S c_{1}$.

When $?=\phi$ and $S c_{1}(X, P, I) \neq \phi$, each element of $S c_{1}(X, P, I)$ is an ordinal scale on $X$.

\subsection{Type $1+2$ Scale}

Suppose that type $1+2$ information $\left\{P, I, ?, P^{e}\right\}$ about $X$ is available.

Definition 4 A type $1+2$ scale on $X$ relative to $\left\{P, I, ?, P^{e}\right\}$ is a function $\mu: X \rightarrow \mathbb{R}$ satisfying Condition 1 and Condition 2.

Condition $2 \forall x, y, z, w \in X,\left[(x, y) P^{e}(z, w) \Rightarrow \mu(x)-\mu(y)>\mu(z)-\right.$ $\mu(w)]$.

Let $S c_{1+2}\left(X, P, I, P^{e}\right)=\{\mu: X \rightarrow \mathbb{R} \mid \mu$ is a type $1+2$ scale on $X$ relative to $\left.\left\{P, I, P^{e}\right\}\right\}$. When $X, P, I$ and $P^{e}$ are well determined, $S c_{1+2}\left(X, P, I, P^{e}\right)$ will be noted $S c_{1+2}$.

\section{Consistency - Inconsistency}

Definition 5 Type 1 information $\{P, I, ?\}$ about $X$ is

- consistent when $S c_{1}(X, P, I) \neq \phi$

- inconsistent when $S c_{1}(X, P, I)=\phi$.

Definition 6 Type $1+2$ information $\left\{P, I, ?, P^{e}\right\}$ about $X$ is 
- consistent when $S c_{1+2}\left(X, P, I, P^{e}\right) \neq \phi$

- inconsistent when $S c_{1+2}\left(X, P, I, P^{e}\right)=\phi$.

When $S c_{1+2}\left(X, P, I, P^{e}\right)=\phi$, one can have $S c_{1}(X, P, I)=\phi$ or $S c_{1}(X, P, I) \neq \phi$. In the first case, the message "no ranking" will appear in M-MACBETH; it occurs namely when $J$ declares, in regards to elements $x, y$ and $z$ of $X$, that $[x I y, y I z$ and $x P z]$ or $[x P y, y P z$ and $z P x]$. In the second case, the message "inconsistent judgement" will appear in M-MACBETH.

Although this is the only difference between the types of inconsistency introduced in M-MACBETH, it is interesting to mention, from a theoretical perspective, that one could further distinguish two sub-types of inconsistency (sub-type a and sub-type b) when $S c_{1+2}\left(X, P, I, P^{e}\right)=\phi$ and $S c_{1}(X, P, I) \neq \phi$.

Sub-type $a$ inconsistency arises when there is a conflict between type 1 information and $P^{e}$ that makes the simultaneous satisfaction of conditions 1 and 2 impossible. These kinds of conflicts are found essentially in four types of situations; namely when $x, y, z \in X$ exist such that

$$
\begin{array}{ll} 
& {\left[x P y, y P z, x P z \text { and }(y, z) P^{e}(x, z)\right]} \\
\text { or } \quad & {\left[x P y, y P z, x P z \text { and }(x, y) P^{e}(x, z)\right]} \\
\text { or } \quad & {\left[x I y, y P z, x P z \text { and }(x, z) P^{e}(y, z)\right]} \\
\text { or } \quad\left[x I y, z P y, z P x \text { and }(z, x) P^{e}(z, y)\right] .
\end{array}
$$

Sub-type $b$ inconsistency arises when there is no conflict between type 1 information and $P^{e}$ but at least one conflict exists inside $P^{e}$ that makes satisfying Condition 2 impossible. An example of this type of conflict is (see Figure 1.1):

$$
\begin{gathered}
x P y, x P w, y P z, w P z, x P z, y P w \\
(x, y) \in C_{1},(y, z) \in C_{2} \\
(x, w) \in C_{3},(w, z) \in C_{2} .
\end{gathered}
$$

In such a case, Condition 2 cannot be respected, because one should have

$$
\left\{\begin{array}{l}
\mu(x)-\mu(w)>\mu(y)-\mu(z) \\
\mu(w)-\mu(z)>\mu(x)-\mu(y)
\end{array}\right.
$$

which is impossible.

On the other hand, it is easily shown that the following two systems are compatible, that is, there is no conflict between type 1 information and $P^{e}$ : 


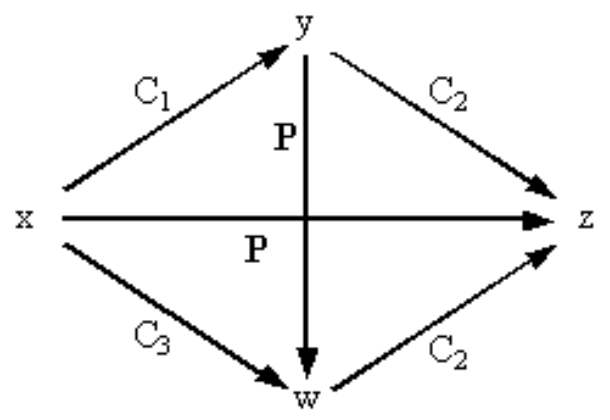

Figure 1.1. Example of sub-type b inconsistency.

$$
\left\{\begin{array} { l } 
{ \mu ( x ) - \mu ( w ) > \mu ( y ) - \mu ( z ) } \\
{ \mu ( x ) - \mu ( y ) > 0 } \\
{ \mu ( x ) - \mu ( w ) > 0 } \\
{ \mu ( x ) - \mu ( z ) > 0 } \\
{ \mu ( y ) - \mu ( z ) > 0 } \\
{ \mu ( w ) - \mu ( z ) > 0 } \\
{ \mu ( y ) - \mu ( w ) > 0 }
\end{array} \quad \left\{\begin{array}{l}
\mu(w)-\mu(z)>\mu(x)-\mu(y) \\
\mu(x)-\mu(y)>0 \\
\mu(x)-\mu(w)>0 \\
\mu(x)-\mu(z)>0 \\
\mu(y)-\mu(z)>0 \\
\mu(w)-\mu(z)>0 \\
\mu(y)-\mu(w)>0
\end{array}\right.\right.
$$

For a detailed study of inconsistency, see [46].

\section{Consistency Test for Preferential Information}

\subsection{Testing Procedures}

Suppose that $X=\left\{a_{1}, a_{2}, \ldots, a_{n}\right\}$.

During the interactive questioning process conducted with $J$, each time that a new judgement is obtained, the consistency of all the responses already provided is tested. This consistency test begins with a pre-test aimed at detecting the (potential) presence of cycles within the relation $P$ and, if no such cycle exists, making a permutation of the elements of $X$ in such a way that, in the matrix of judgements, all of the cells $P$ or $C_{i j}$ will be located above the main diagonal.

When there is no cycle in $P$, the consistency of type 1 information $\{P, I, ?\}$ is tested as follows:

- If $? \neq \phi$, a linear program named LP-test ${ }_{1}$ is used;

- if $?=\phi$, rather than linear programming, a method named DIRtest $_{1}$ is used, which has the advantage of being easily associated with a very simple visualization of an eventual ranking within the matrix of judgements. 
When $\{P, I, ?\}$ is consistent, the consistency of type $1+2$ information $\left\{P, I, ?, P^{e}\right\}$ is tested with the help of a linear program named $\operatorname{LP} \sigma$ test $_{1+2}$.

\subsection{Pre-test of the Preferential Information}

The pre-test of the preferential information is based on Property 1. (Evident because $\# X$ is finite).

Property 1 Let $X^{*} \subset X$; if $\forall x \in X^{*}, \exists y \in X^{*}$ such that $x P y$, then $\exists x_{1}, x_{2}, \ldots, x_{p} \in X^{*}$ such that $x_{1} P x_{2} P \ldots P x_{p} P x_{1}$ (cycle).

The pre-test consists of seeking a permutation $\varphi: \mathbb{N}_{1, n} \rightarrow \mathbb{N}_{1, n}$ such that

$$
\forall i, j \in \mathbb{N}_{1, n}, \quad\left[i>j \Rightarrow a_{\varphi(i)}(\operatorname{not} P) a_{\varphi(j)}\right] .
$$

The permutation of the elements of $X$ is made by the algorithm PRETEST, that detects cycles within $P$ and sorts the elements(s) of $X$.

PRETEST:

$1 s \leftarrow n$;

2 among $a_{1}, a_{2}, \ldots, a_{s}$ find $a_{i}$ which is not preferred over any other: if $a_{i}$ exists, go to 3 ;

if not, return FALSE $\left(S c_{1}=\phi\right.$, according to Property 1); finish.

3 permute $a_{i}$ and $a_{s}$;

$4 s \leftarrow s-1:$

if $s=1$, return TRUE; finish.

If not, go to 2 .

\subsection{Consistency Test for Type 1 Information}

Suppose that PRETEST detected no cycle within $P$ and that the elements of $X$ were renumbered as follows (to avoid the introduction of a permutation in the notation):

$$
\forall i, j \in \mathbb{N}_{1, n},\left[i>j \Rightarrow a_{i}(\operatorname{not} P) a_{j}\right] .
$$

6.3.1 Consistency Test for Incomplete $(? \neq \phi)$ Type 1 Information. Consider the linear program LP-test ${ }_{1}$ with variables $x_{1}, x_{2}, \ldots, x_{n}$ : 


$$
\begin{array}{ll}
\min x_{1} & \\
\text { subject to } & \\
x_{i}-x_{j} \geq d_{\min } & \forall\left(a_{i}, a_{j}\right) \in P \\
x_{i}-x_{j}=0 & \forall\left(a_{i}, a_{j}\right) \in I \text { with } i \neq j \\
x_{i} \geq 0 & \forall i \in \mathbb{N}_{1, n}
\end{array}
$$

where $d_{\min }$ is a positive constant, and the variables $x_{1}, x_{2}, \ldots, x_{n}$ represent the numbers $\mu\left(a_{1}\right), \mu\left(a_{2}\right), \ldots, \mu\left(a_{n}\right)$ that should satisfy Condition 1 so that $\mu$ is a type 1 scale.

The objective function min $x_{1}$ of LP-test ${ }_{1}$ is obviously arbitrary. It is trivial that $S c_{1} \neq \phi \Leftrightarrow$ LP-test $_{1}$ is feasible.

\subsubsection{Consistency Test for Complete $(?=\phi)$ Type 1 Infor-} mation. When $?=\phi$ and the elements of $X$ have been renumbered (after the application of PRETEST), another simple test (DIR-test ${ }_{1}$ ) allows one to verify if $P \cup I$ is a complete preorder on $X$. DIR-test D $_{1}$ is based on Proposition 1 (Proved in [46]).

Proposition 1 If $\left[\forall i, j \in \mathbb{N}_{1, n}\right.$ with $\left.i<j,\left(a_{i}, a_{j}\right) \in P \cup I\right]$ then $P \cup I$ is a complete preorder on $X$ if and only if $\forall i, j \in \mathbb{N}_{1, n}$ with $i<j$ : $\left[a_{i} P a_{j} \Rightarrow\left\{\begin{array}{l}\forall s \leq i, \forall t \geq j, a_{s} P a_{t} \\ \exists s: i \leq s \leq j-1 \text { and } a_{s} P a_{s+1}\end{array}\right]\right.$.

Proposition 1 means that when the " $P$ cases" of the matrix of judgements forms a "staircase", a ranking exists such that each step of the "staircase" rests, at least partly, on the principal diagonal of the matrix.

\subsection{Consistency Test for Type 1+2 Information}

It would be possible to test the consistency of type $1+2$ information with a linear program based on Conditions 1 and 2. However, the more efficient linear program LP-test ${ }_{1+2}$, which includes "thresholds conditions" equivalent to Conditions 1 and 2, is used instead. LP-test L $_{1+2}$ is based on Lemma 1 (Proved in [46]).

Lemma 1 Let $\mu: X \rightarrow \mathbb{R} . \mu$ satisfies Conditions 1 and 2 if and only if there exist $Q$ "thresholds" $0<\sigma_{1}<\sigma_{2}<\ldots<\sigma_{Q}$ that satisfy Conditions 3, 4 and 5.

Condition $3 \forall(x, y) \in I, \mu(x)=\mu(y)$.

Condition $4 \forall i, j \in \mathbb{N}_{1, Q}$ with $i \leq j, \forall(x, y) \in C_{i j}, \sigma_{i}<\mu(x)-\mu(y)$.

Condition $5 \forall i, j \in \mathbb{N}_{1, Q-1}$ with $i \leq j, \forall(x, y) \in C_{i j}, \mu(x)-\mu(y)<$ $\sigma_{j+1}$. 
Program LP-test L $_{1+2}$ has variables $x_{1}\left(=\mu\left(a_{1}\right)\right), \ldots, x_{n}\left(=\mu\left(a_{n}\right)\right), \sigma_{1}, \ldots$, $\sigma_{Q}$ :

$\min x_{1}$

subject to

$x_{p}-x_{r}=0$

$\forall\left(a_{p}, a_{r}\right) \in I$ with $p<r$

$\sigma_{j}+d_{\min } \leq x_{p}-x_{r}$

$\forall i, j \in \mathbb{N}_{1, Q}$ with $i \leq j, \forall\left(a_{p}, a_{r}\right) \in C_{i j}$

$x_{p}-x_{r} \leq \sigma_{j+1}-d_{\min }$

$\forall i, j \in \mathbb{N}_{1, Q-1}$ with $i \leq j, \forall\left(a_{p}, a_{r}\right) \in C_{i j}$

$d_{\min } \leq \sigma_{1}$

$\sigma_{i-1}+d_{\min } \leq \sigma_{i}$

$\forall i \in \mathbb{N}_{2, Q}$

$x_{i} \geq 0$

$\forall i \in \mathbb{N}_{1, n}$

$\sigma_{i} \geq 0$

$\forall i \in \mathbb{N}_{1, Q}$

Taking into account Lemma 1 , it is trivial that $S c_{1+2} \neq \phi$ if and only if the linear program LP-test ${ }_{1+2}$, which is based on Conditions 3,4 and 5 , is feasible.

\section{Dealing with Inconsistency}

When a type $1+2$ information $\left\{P, I, ?, P^{e}\right\}$ about $X$ is inconsistent, it is convenient to be able to show $J$ systems of constraints that render his or her judgements inconsistent and modifications of these judgements that would render $\mathrm{LP} \sigma$-test $_{1+2}$ feasible.

\subsection{Systems of Incompatible Constraints}

Suppose that LP-test ${ }_{1+2}$ is not feasible or, in other words, that the following system is incompatible (variables $x_{1}\left(=\mu\left(a_{1}\right)\right), \ldots, x_{n}\left(=\mu\left(a_{n}\right)\right)$, $\sigma_{1}, \ldots, \sigma_{Q}$ nonnegative):

$$
\begin{cases}x_{p}-x_{r}=0 & \forall\left(a_{p}, a_{r}\right) \in I \text { with } p<r \\ \sigma_{i}<x_{p}-x_{r} & \forall i, j \in \mathbb{N}_{1, Q} \text { with } i \leq j, \forall\left(a_{p}, a_{r}\right) \in C_{i j} \\ x_{p}-x_{r}<\sigma_{j+1} & \forall i, j \in \mathbb{N}_{1, Q-1} \text { with } i \leq j, \forall\left(a_{p}, a_{r}\right) \in C_{i j} \\ 0<\sigma_{1} & \forall i \in \mathbb{N}_{2, Q} \\ \sigma_{i-1}<\sigma_{i} & \end{cases}
$$

Conventions:

- $\mathbb{R}^{m \times n}$ is the set of the real matrices with $m$ lines and $n$ columns.

- Matrix $M \in \mathbb{R}^{m \times n}$ is "non-zero" $(M \neq 0)$ if at least one of its elements is not null.

- Matrix $M \in \mathbb{R}^{m \times n}$ is positive or null $(M \geq 0)$ if all of its elements are positive or null. 
The system of incompatible constraints can be written in the matrix format as follows:

$$
\begin{cases}C \cdot Z>0 & \text { (by grouping constraints }(\mathrm{t} 2)) \\ D \cdot Z>0 & \text { (by grouping constraints }(\mathrm{t} 3)) \\ E \cdot Z>0 & \text { (by grouping constraints }(\mathrm{t} 4) \text { and }(\mathrm{t} 5)) \\ B \cdot Z=0 & \text { (by grouping constraints }(\mathrm{t} 1))\end{cases}
$$

where

$$
Z=\left(\begin{array}{c}
x_{1} \\
x_{2} \\
\vdots \\
x_{n} \\
\sigma_{1} \\
\sigma_{2} \\
\vdots \\
\sigma_{Q}
\end{array}\right)
$$

$C \in \mathbb{R}^{p_{1} \times(n+Q)}$ (where $p_{1}$ is the number of constraints (t2))

$D \in \mathbb{R}^{p_{2} \times(n+Q)}$ (where $p_{2}$ is the number of constraints (t3))

$E \in \mathbb{R}^{p_{3} \times(n+Q)}$ (where $p_{3}$ is the number of constraints (t4) and (t5))

$B \in \mathbb{R}^{r \times(n+Q)}$ (where $r$ is the number of constraints (t1))

Note: if $r=0$, one could consider that $B=0 \in \mathbb{R}^{1 \times(n+Q)}$ without losing generality.

Let $A$ be the matrix $\left[\begin{array}{c}C \\ D \\ E\end{array}\right] \in \mathbb{R}^{p \times(n+Q)} \quad\left(p=p_{1}+p_{2}+p_{3}\right)$. The system of incompatible constraints can be written more simply as

$S \begin{cases}A \cdot Z>0 & \text { (by grouping constraints (t2), (t3), (t4) and (t5)) } \\ B \cdot Z=0 & \text { (by grouping constraints (t1)). }\end{cases}$

In order to detect incompatibilities between the constraints (t1), (t2), (t3), (t4) and (t5) and propose eventual corrections, we apply Proposition 2 (Proved in [46]), which is a corollary of Mangasarian's [55] version of the Theorem of the Alternative. 
Proposition 2 The system $S \quad\left\{\begin{array}{l}A \cdot Z>0 \\ B \cdot Z=0\end{array}\right.$ admits a solution $Z \in$ $\mathbb{R}^{(n+Q) \times 1}$ or there exists $Y \in \mathbb{R}^{p \times 1}, V, W \in \mathbb{R}^{r \times 1}$ with $Y \neq 0, Y \geq 0, V \geq$ $0, W \geq 0$ such that ${ }^{t} A \cdot Y+{ }^{t} B \cdot(V-W)=0$ and $\forall i \in \mathbb{N}_{1, r}, V_{i} \cdot W_{i}=0$ but never both.

The interest of Proposition 2 is that vectors $Y, V$ and $W$ have positive or null components, thus making it compatible with linear programming (see Sections 7.3 and 7.4)

\subsection{Example 1}

Suppose that $X=\left\{a_{1}, a_{2}, a_{3}, a_{4}\right\}$ and that $J$ has formulated the following judgements:

- $P=\left\{\left(a_{1}, a_{2}\right),\left(a_{1}, a_{3}\right),\left(a_{2}, a_{3}\right),\left(a_{3}, a_{4}\right)\right\}$

- $\left(a_{1}, a_{2}\right) \in C_{1},\left(a_{1}, a_{3}\right) \in C_{4},\left(a_{2}, a_{3}\right) \in C_{2},\left(a_{3}, a_{4}\right) \in C_{2}$.

Suppose that $J$ also judges that $a_{2} \mathrm{~Pa}_{4}$ and that $\left(a_{2}, a_{4}\right) \in C_{3}$. LPtest $_{1}$ is feasible: the judgements are compatible with a ranking. LPtest $_{1+2}$ is not feasible: the software informs $J$ that his or her judgements are "inconsistent".

Suppose now that $J$ confirms his or her judgements. One must then have:

$$
\begin{array}{llllc}
\sigma_{1}<x_{1}-x_{2} & (1) & x_{1}-x_{2}<\sigma_{2} & (2) & 0<\sigma_{1} \\
\sigma_{2}<x_{2}-x_{3} & (3) & x_{2}-x_{3}<\sigma_{3} & (4) & \sigma_{1}<\sigma_{2} \\
\sigma_{2}<x_{3}-x_{4} & (5) & x_{3}-x_{4}<\sigma_{3} & (6) & \sigma_{2}<\sigma_{3} \\
\sigma_{3}<x_{2}-x_{4} & (7) & x_{2}-x_{4}<\sigma_{4} & (8) & \sigma_{3}<\sigma_{4} \\
\sigma_{4}<x_{1}-x_{3} & (9) & x_{1}-x_{3}<\sigma_{5} & (10) & \sigma_{4}<\sigma_{5} \\
& & & & \sigma_{5}<\sigma_{6}
\end{array}
$$

or, in matrix format (which one can denote as $A \cdot Z>0$ ): 


$$
\left(\begin{array}{rrrrrrrrrr}
1 & -1 & 0 & 0 & -1 & 0 & 0 & 0 & 0 & 0 \\
-1 & 1 & 0 & 0 & 0 & 1 & 0 & 0 & 0 & 0 \\
0 & 1 & -1 & 0 & 0 & -1 & 0 & 0 & 0 & 0 \\
0 & -1 & 1 & 0 & 0 & 0 & 1 & 0 & 0 & 0 \\
0 & 0 & 1 & -1 & 0 & -1 & 0 & 0 & 0 & 0 \\
0 & 0 & -1 & 1 & 0 & 0 & 1 & 0 & 0 & 0 \\
0 & 1 & 0 & -1 & 0 & 0 & -1 & 0 & 0 & 0 \\
0 & -1 & 0 & 1 & 0 & 0 & 0 & 1 & 0 & 0 \\
1 & 0 & -1 & 0 & 0 & 0 & 0 & -1 & 0 & 0 \\
-1 & 0 & 1 & 0 & 0 & 0 & 0 & 0 & 1 & 0 \\
0 & 0 & 0 & 0 & 1 & 0 & 0 & 0 & 0 & 0 \\
0 & 0 & 0 & 0 & -1 & 1 & 0 & 0 & 0 & 0 \\
0 & 0 & 0 & 0 & 0 & -1 & 1 & 0 & 0 & 0 \\
0 & 0 & 0 & 0 & 0 & 0 & -1 & 1 & 0 & 0 \\
0 & 0 & 0 & 0 & 0 & 0 & 0 & -1 & 1 & 0 \\
0 & 0 & 0 & 0 & 0 & 0 & 0 & 0 & -1 & 1
\end{array}\right) \quad \cdot \quad\left(\begin{array}{l}
x_{1} \\
x_{2} \\
x_{3} \\
x_{4} \\
\sigma_{1} \\
\sigma_{2} \\
\sigma_{3} \\
\sigma_{4} \\
\sigma_{5} \\
\sigma_{6}
\end{array}\right)>0
$$

Since it is known, according to Proposition 2, that the system has no solution, there necessarily exists $Y \in \mathbb{R}^{16 \times 1}(Y \neq 0, Y \geq 0)$ such that ${ }^{t} A \cdot Y=0$. Thus, positive or null (but not all null) real numbers $y_{1}, y_{2}, \ldots, y_{16}$ exist such that $\sum_{i=1}^{16} y_{i} \cdot \operatorname{Col}_{i}=0$ (where $\operatorname{Col}_{i}$ is the column $i$ of the matrix ${ }^{t} A$ ).

In this simple example, one can see that it is enough to make $y_{2}=$ $y_{5}=y_{8}=y_{9}=1$ and $y_{1}=y_{3}=y_{4}=y_{6}=y_{7}=y_{10}=y_{11}=y_{12}=y_{13}=$ $y_{14}=y_{15}=y_{16}=0$ :

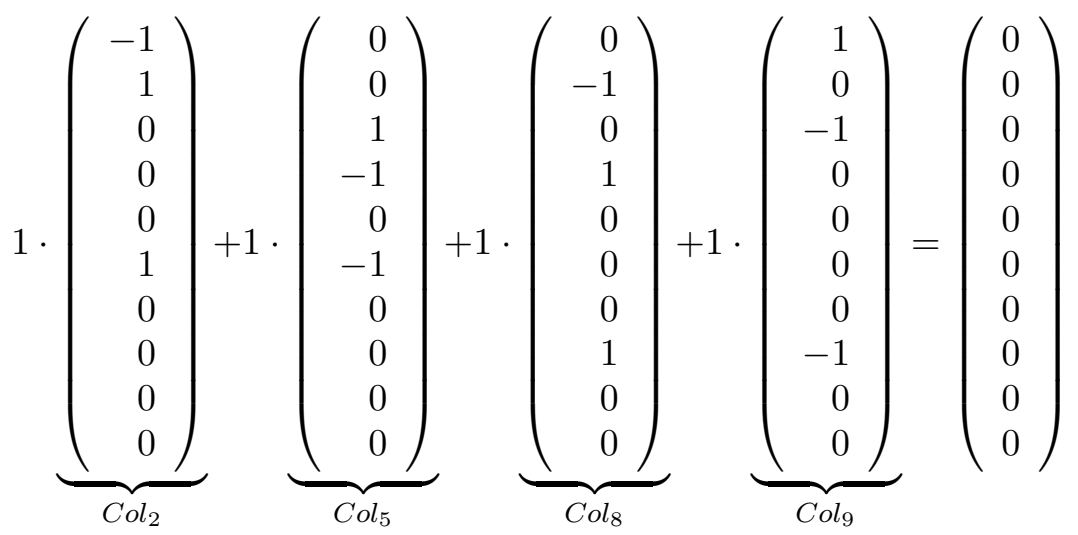

These four vectors correspond to the four constraints (2), (5), (8) and (9) above:

$$
\left.\begin{array}{ll}
\sigma_{4}>x_{2}-x_{4} & (8) \\
x_{1}-x_{3}>\sigma_{4} & (9)
\end{array}\right\} \Rightarrow x_{1}-x_{3}>x_{2}-x_{4}
$$




$$
\left.\begin{array}{ll}
\sigma_{2}>x_{1}-x_{2} & (2) \\
x_{3}-x_{4}>\sigma_{2} & (5)
\end{array}\right\} \Rightarrow x_{3}-x_{4}>x_{1}-x_{2} \quad(* *)
$$

$(*)$ and $(* *)$ bring to the contradiction $x_{1}-x_{4}>x_{1}-x_{4}$. The incompatibility between $(*)$ and $(* *)$ is presented in M-MACBETH as shown in Figure 1.2.

\begin{tabular}{|c|ccc|c|}
\hline Diff. & Couples & Couples & Diff. \\
\hline strong & $\mathrm{a} 1 \cdot \mathrm{a} 3$ & $>\mathrm{a} 2 \cdot \mathrm{a} 4$ & moderate \\
\hline weak & $\mathrm{a} 3 \cdot \mathrm{a} 4$ & $>\mathrm{a} 1 \cdot \mathrm{a} 2$ & very weak \\
\hline
\end{tabular}

Figure 1.2. Example of incompatibility between $(*)$ and $(* *)$.

Note that the problem disappears if

$$
\begin{array}{llll} 
& \left(a_{1}, a_{3}\right) \in C_{3} \text { instead of } C_{4} & ((*) \text { disappears }) \\
\text { or } & \left(a_{2}, a_{4}\right) \in C_{4} \text { instead of } C_{3} & ((*) \text { disappears }) \\
\text { or } & \left(a_{3}, a_{4}\right) \in C_{1} \text { instead of } C_{2} & ((* *) \text { disappears }) \\
\text { or } & \left(a_{1}, a_{2}\right) \in C_{2} \text { instead of } C_{1} & ((* *) \text { disappears }) .
\end{array}
$$

Note also that the inconsistency would not be eliminated for any modification of the judgement " $\left(a_{2}, a_{3}\right) \in C_{2}$ ".

If $J$ confirms the judgement " $\left(a_{2}, a_{4}\right) \in C_{3}$ ", M-MACBETH calculates the different possibilities (four in example 1 ) that $J$ can follow to make his or her judgements consistent with a "minimal" number of changes of category (one in Example 1). (We will specify in Section 7.4 the meaning of this notion).

In M-MACBETH, the "suggestions" of changes are presented (graphically) in the matrix of judgements. They are:

- to replace the judgement $\left(a_{1}, a_{3}\right) \in C_{4}$ with the judgement $\left(a_{1}, a_{3}\right)$ $\in C_{3}$

- or to replace the judgement $\left(a_{2}, a_{4}\right) \in C_{3}$ with the judgement $\left(a_{2}, a_{4}\right) \in C_{4}$

- or to replace the judgement $\left(a_{3}, a_{4}\right) \in C_{2}$ with the judgement $\left(a_{3}, a_{4}\right) \in C_{1}$

- or to replace the judgement $\left(a_{1}, a_{2}\right) \in C_{1}$ with the judgement $\left(a_{1}, a_{2}\right) \in C_{2}$.

\subsection{Identifying Constraints which Cause Inconsistency}

Let us detail the various stages of our search for "suggestions". The first step consists of determining the constraints (t1), (t2) and (t3) which are 
"the origin of the incompatibilities" present in the system

$$
S\left\{\begin{array}{l}
A \cdot Z>0 \\
B \cdot Z=0
\end{array} \quad \text { (see Section } 7.1\right)
$$

We consider that a constraint is "at the origin of an incompatibility" when it is part of a system $S^{\prime}$ that

- is a "sub-system" of $\mathrm{S}$,

- is incompatible,

- does not contain any incompatible "sub-system".

Mathematically, this idea can be represented by Definition 7 .

Definition 7 An incompatible elementary system (SEI) is a system

$$
S^{\prime}\left\{\begin{array}{l}
A^{\prime} \cdot Z>0 \\
B^{\prime} \cdot Z=0
\end{array}\right.
$$

such that

$1 A^{\prime} \in \mathbb{R}^{p^{\prime} \times(n+Q)}$ is a sub-matrix of $A$, and $B^{\prime} \in \mathbb{R}^{r^{\prime} \times(n+Q)}$ is a sub-matrix of $B$;

$2 S^{\prime}$ is incompatible;

$$
\begin{aligned}
& 3 \text { If }\left\{\begin{array} { l } 
{ A ^ { \prime \prime } \in \mathbb { R } ^ { p ^ { \prime \prime } \times ( n + Q ) } \text { is a sub-matrix of } A ^ { \prime } , } \\
{ B ^ { \prime \prime } \in \mathbb { R } ^ { r ^ { \prime \prime } \times ( n + Q ) } \text { is a sub-matrix of } B ^ { \prime } , } \\
{ p ^ { \prime \prime } + r ^ { \prime \prime } < p ^ { \prime } + r ^ { \prime } }
\end{array} \text { then } \left\{\begin{array}{l}
A^{\prime \prime} \cdot Z>0 \\
B^{\prime \prime} \cdot Z=0
\end{array}\right.\right. \\
& \text { is compatible. }
\end{aligned}
$$

However, our goal is not to determine all the SEI that could be extracted from the constraints using $\mathrm{LP} \sigma$-test ${ }_{1+2}$. We just want to find all of the judgements of the type $\left(a_{s}, a_{t}\right) \in C_{i j}$ that "generate" an incompatibility. In Section 7.4.3, we will explain how we use these judgements.

We know that an inconsistency occurs when the system

$$
S\left\{\begin{array}{l}
A \cdot Z>0 \\
B \cdot Z=0
\end{array}\right.
$$

is incompatible; that is, $\exists Y \in \mathbb{R}^{p}$ and $V, W \in \mathbb{R}^{r}$ such that

$$
\left\{\begin{array}{l}
{ }^{t} A \cdot Y+{ }^{t} B \cdot(V-W)=0 \\
Y \geq 0, V \geq 0, W \geq 0 \\
\forall i \in \mathbb{N}_{1, r}, V_{i} \cdot W_{i}=0 \\
\exists i_{0} \in \mathbb{N}_{1, p} \text { such that } Y_{i_{0}} \neq 0
\end{array}\right.
$$


In such a case, if $i_{0} \leq p_{1}+p_{2}$, where $p_{1}$ is the number of constraints (t2) and $p_{2}$ is the number of constraints (t3) (see Section 7.1), a constraint of the type $x_{s}-x_{t}<\sigma_{j}$ or $x_{s}-x_{t}>\sigma_{j}$ will correspond to $S$.

Consider, then, the system (with $i \leq p_{1}+p_{2}$ ):

$$
\text { Syst- } Y_{i}\left\{\begin{array}{l}
{ }^{t} A \cdot Y+{ }^{t} B \cdot(V-W)=0 \\
Y_{i}=1
\end{array}\right.
$$

If Syst- $Y_{i}$ is compatible, for one of its solutions it corresponds to a system of incompatible constraints (t1), (t2), (t3), (t4) and (t5) where at least one constraint (that which corresponds to $Y_{i}=1$ ) is of the type $x_{s}-x_{t}<\sigma_{j}$ or $x_{s}-x_{t}>\sigma_{j}$ and is part of a SEI. If Syst- $Y_{i}$ is incompatible, the constraint that corresponds to $Y_{i}$ is not part of any SEI.

To find all of the constraints (t2) and (t3) which are part of a SEI, it is sufficient to study the compatibility of all of the systems Syst- $Y_{i}$, for $i=1,2, \ldots, p_{1}+p_{2}$.

We will proceed in a similar way, using the systems Syst- $V_{i}$ and Syst$W_{i}$, to find all of the constraints (t1) which are part of a SEI:

$$
\text { Syst- } V_{i}\left\{\begin{array}{l}
{ }^{t} A \cdot Y+{ }^{t} B \cdot(V-W)=0 \\
W_{i}=0 \\
V_{i}=1
\end{array}\right.
$$

and

$$
\text { Syst- } W_{i}\left\{\begin{array}{l}
{ }^{t} A \cdot Y+{ }^{t} B \cdot(V-W)=0 \\
V_{i}=0 \\
W_{i}=1
\end{array}\right.
$$

It is not necessary to examine all of the systems Syst- $Y_{i}$, Syst- $V_{i}$ and Syst- $W_{i}$ :

- If Syst- $Y_{i}$ is compatible and has the solution $Y, V, W$, then

- $\forall j>i$ such that $Y_{j} \neq 0$, Syst- $Y_{i}$ is compatible;

- $\forall j \in \mathbb{N}_{1, r}$ such that $V_{j} \neq 0$, Syst- $V_{i}$ is compatible;

- $\forall j \in \mathbb{N}_{1, r}$ such that $W_{j} \neq 0$, Syst- $W_{i}$ is compatible.

- If Syst- $V_{i}$ is compatible and has the solution $Y, V, W$, then

$-\forall j>i$ such that $V_{j} \neq 0$, Syst- $V_{i}$ is compatible;

$-\forall j \in \mathbb{N}_{1, r}$ such that $W_{j} \neq 0$, Syst- $W_{i}$ is compatible.

- If Syst- $W_{i}$ is compatible and has the solution $Y, V, W$, then

$-\forall j>i$ such that $W_{j} \neq 0$, Syst- $W_{i}$ is compatible. 
It is for this reason that a "witness-vector" $T \in \mathbb{N}^{p_{1}+p_{2}+2 \cdot r}$ must be used, initially null, updated as follows:

- For any solution $Y, V, W$ of a system $\operatorname{Syst}-Y_{i}$, Syst- $V_{i}$ or Syst- $W_{i}$ do

$$
\begin{aligned}
& -\forall j \in \mathbb{N}_{1, p_{1}+p_{2}},\left[Y_{j} \neq 0 \Rightarrow T_{j}=1\right] \\
& -\forall j \in \mathbb{N}_{1, r},\left[V_{j} \neq 0 \Rightarrow T_{p_{1}+p_{2}+j}=1\right] \\
& - \text { and }\left[W_{j} \neq 0 \Rightarrow T_{p_{1}+p_{2}+r+j}=1\right] .
\end{aligned}
$$

To find the interesting pairs, the compatibility of at most $p_{1}+p_{2}+2 r$ systems should be studied. The general algorithm to seek equations (t1) and inequalities (t2) and (t3) that are part of a SEI is the following:

- $T=(0,0, \ldots, 0)$

- for $i=1,2, \ldots, p_{1}+p_{2}$ do:

$-T_{i}=0$,

- then if Syst- $Y_{i}$ compatible and $Y, V, W$ solution of Syst- $Y_{i}$

then update $T$

- for $i=1,2, \ldots, r$ do:

- if $T_{p_{1}+p_{2}+i}=0$,

- then if Syst- $V_{i}$ compatible and $Y, V, W$ solution of Syst- $V_{i}$

then update $T$

- for $i=1,2, \ldots, r$ do:

- if $T_{p_{1}+p_{2}+r+i}=0$,

- then if Syst- $W_{i}$ compatible and $Y, V, W$ solution of Syst- $W_{i}$

then update $T$.

In this way one obtains the set of all of the equations and inequalities that make up the SEI.

\subsection{Augmentation - Reduction in a Judgement with $p$ Categories}

\subsubsection{Preliminaries. Notation:}

- Judgement $(x, y) \in C_{i j}$ will be represented by element $(x, y, i, j)$ of $X \times X \times \mathbb{N}_{1, Q} \times \mathbb{N}_{1, Q}$. 
- Judgement $(x, y) \in I$ will be represented by element $(x, y, 0,0)$ of $X \times X \times \mathbb{N} \times \mathbb{N}$.

Definition 8 A reduction in judgement $(s, t, i, j)$ with $p$ categories $(1 \leq$ $p \leq Q+i)$ is the replacement of this judgement

- by the judgement $(s, t, i-p, i-p)$ if $i \geq p$

- by the judgement $(t, s, p-i, p-i)$ if $i<p$.

Definition 9 An augmentation of the judgement $(s, t, i, j)$ with $p$ categories $(1 \leq p \leq Q-j)$ is the replacement of this judgement by the judgement $(s, t, j+p, j+p)$.

Definition 10 A change of judgement $(s, t, i, j)$ with $p$ categories is an augmentation or a reduction of the judgement with $p$ categories.

Comment: It is evident that one obtains the same final judgement as a result of " 1 reduction of a judgement with p categories" or the "p successive reductions of a category of 1 judgement".

Convention: A "change in judgement $(s, t, i, j)$ with $p$ categories" will be represented by $(s, t, i, j, p) \in X \times X \times \mathbb{N}_{1, Q} \times \mathbb{N}_{1, Q} \times \mathbb{Z}$ (augmentation if $p>0$, reduction if $p<0$ ).

7.4.2 Exploitation of the Constraints of SEI. Let us recall from 7.3 that

- if $T_{i}>0$, it has a corresponding constraint (t2) or (t3) or (t1) that is part of an SEI;

- if $T_{i}=0$, it has no corresponding constraint that is part of an SEI.

These variables, then, provide us with an indication as to the future "modification" to be made to the judgements associated with these constraints. Indeed, suppose that $T_{i}>0$ :

a) if $1 \leq i \leq p_{1}$, a constraint $\sigma_{u}<x_{s}-x_{t}$ which is part of an SEI corresponds to variable $T_{i}$; if a change in its judgement $(s, t, \ldots, \ldots)$ can help to eliminate the SEI, it ensures that it will be a "reduction" (evident).

b) if $p_{1}+1 \leq i \leq p_{1}+p_{2}$, a constraint $x_{s}-x_{t}<\sigma_{u}$ which is part of an SEI corresponds to variable $T_{i}$; if a change in its judgement $(s, t, \ldots, \ldots)$ can help to eliminate the SEI, it ensures that it will be an "augmentation" (evident).

c) if $p_{1}+p_{2}+1 \leq i \leq p_{1}+p_{2}+r$, a constraint $x_{s}-x_{t}=0$ which is part of an SEI corresponds to variable $T_{i}$; if a change in its judgement 
$(s, t, 0,0)$ can help to eliminate the SEI, it ensures that it will be a "reduction".

d) if $p_{1}+p_{2}+r+1 \leq i \leq p_{1}+p_{2}+2 r$, a constraint $x_{s}-x_{t}=0$ which is part of an SEI corresponds to variable $T_{i}$; if a change in its judgement $(s, t, 0,0)$ can help to eliminate the SEI, it ensures that it will be an "augmentation" (proof similar to that of c).

Proof of c):

Being $h=i-\left(p_{1}+p_{2}\right)$, one knows (by the definition of $\left.T_{i}\right)$ that $\exists Y \in \mathbb{R}^{p}, \exists V, W \in \mathbb{R}^{r}$ with $Y \geq 0, V \geq 0, W \geq 0, Y \neq 0, V_{h} \neq 0$ and $W_{h}=0$ such that ${ }^{t}\left(A^{\prime}\right) \cdot Y+{ }^{t}\left(B^{\prime}\right) \cdot(V-W)=0$ or, if one notes Line $B_{j}$ the $j$ th line of $B^{\prime}$,

$$
{ }^{t}\left(A^{\prime}\right) \cdot Y+{ }^{t} \text { Line }_{h} \cdot V_{h}+\sum_{\substack{j=1 \\ j \neq h}}^{r}{ }^{t} \text { Line }_{j} \cdot V_{j}-\sum_{\substack{j=1 \\ j \neq h}}^{r}{ }^{t} \text { Line }_{j} \cdot W_{j}=0
$$

(because $W_{h}=0$ ).

The corresponding SEI $\left\{\begin{array}{l}A^{\prime} \cdot Z>0 \\ B^{\prime} \cdot Z=0\end{array}\right.$ can be written $\left\{\begin{array}{l}A^{\prime} \cdot Z>0 \\ x_{s}-x_{t}=0 \\ B^{\prime \prime} \cdot Z=0\end{array}\right.$ where $B^{\prime \prime}=\left[\begin{array}{c}\text { Line }_{1} \\ \vdots \\ \text { Line }_{h-1} \\ \text { Line } B_{h+1} \\ \vdots \\ \text { Line } B_{r}\end{array}\right]$ (the matrix $B^{\prime}$ without line Line $\left.B_{h}\right)$.

If one considers an "augmentation" of judgement $(s, t, 0,0)$, the constraint $x_{s}-x_{t}=0$ would be replaced by the constraint $x_{s}-x_{t}>0$. The new system $\left\{\begin{array}{l}A^{\prime} \cdot Z>0 \\ x_{s}-x_{t}>0 \\ B^{\prime \prime} \cdot Z=0\end{array}\right.$ can be written $\left\{\begin{array}{l}A^{\prime \prime} \cdot Z>0 \\ B^{\prime \prime} \cdot Z=0,\end{array}\right.$ where $A^{\prime \prime}=\left[\begin{array}{c}A^{\prime} \\ \text { Line }_{h}\end{array}\right]$ (the matrix $A^{\prime}$ "augmented" with line Line $B_{h}$ ).

The system is still incompatible; indeed, if one poses

- $Y^{\prime}=\left(Y_{1}, Y_{2}, \ldots, Y_{p}, V_{h}\right) \in \mathbb{N}^{p+1}$

- $V^{\prime}=\left(V_{1}, \ldots, V_{h-1}, V_{h+1}, \ldots, V_{r}\right) \in \mathbb{N}^{r-1}$

- $W^{\prime}=\left(W_{1}, \ldots, W_{h-1}, W_{h+1}, \ldots, W_{r}\right) \in \mathbb{N}^{r-1}$. 


$$
{ }^{t}\left(A^{\prime}\right) \cdot Y+{ }^{t} \text { Line }_{h} \cdot V_{h}+\sum_{\substack{j=1 \\ j \neq h}}^{r}{ }^{t} \text { Line }_{j} \cdot V_{j}-\sum_{\substack{j=1 \\ j \neq h}}^{r}{ }^{t} \text { Line }_{j} \cdot W_{j}=0
$$

can be written: ${ }^{t}\left(A^{\prime \prime}\right) \cdot Y^{\prime}+{ }^{t}\left(B^{\prime \prime}\right) \cdot\left(V^{\prime}-W^{\prime}\right)=0$, where $Y^{\prime} \neq 0$ (since $Y \neq 0)$, which proves the incompatibility of the system.

Each "suggestion" of a potential change $\left(T_{i}=1\right)$ of a judgement $(s, t, \ldots, \ldots)$ can thus be stored in a vector $S$ of $\mathbb{N}^{4}$ where

$$
\begin{aligned}
& S_{1}=s \\
& S_{2}=t \\
& S_{3}=\left\{\begin{array}{cc}
1 & \text { if } \exists i \in \mathbb{N}_{1, p_{1}} \cup \mathbb{N}_{p_{1}+p_{2}+1, p_{1}+p_{2}+r} \text { such that } T_{i}=1 \\
0 & \text { otherwise }
\end{array}\right. \\
& S_{4}=\left\{\begin{array}{cc}
1 & \text { if } \exists i \in \mathbb{N}_{p_{1}+1, p_{1}+p_{2} \cup \mathbb{N}_{p_{1}+p_{2}+r+1, p_{1}+p_{2}+2 r} \text { such that }} \\
T_{i}=1 \quad \text { (augmentation) } \\
0 & \text { otherwise }
\end{array}\right.
\end{aligned}
$$

We will denote by PreSugg the set of these "pre-suggestions". In the case of example 1 (see Section 7.3) one has

$$
\text { PreSugg }=\left\{\left(a_{1}, a_{3}, 1,0\right),\left(a_{3}, a_{4}, 1,0\right),\left(a_{1}, a_{2}, 0,1\right),\left(a_{2}, a_{4}, 0,1\right)\right\} .
$$

\subsubsection{Search for Suggestions.}

Definition 11 Changing judgements by $m$ categories is any set Modif $f_{m}$ of the form Modif $f_{m}=\left\{\left(s_{1}, t_{1}, i_{1}, j_{1}, p_{1}\right),\left(s_{2}, t_{2}, i_{2}, j_{2}, p_{2}\right), \ldots,\left(s_{u}, t_{u}, i_{u}\right.\right.$, $\left.j_{u}, p_{u}\right) \mid \forall v \in \mathbb{N}_{1, u},\left(s_{v}, t_{v}, i_{v}, j_{v}, p_{v}\right)$ is a change of judgement $\left(s_{v}, t_{v}, i_{v}, j_{v}\right)$ with $p_{v}$ categories\} such that $\sum_{v=1}^{u}\left|p_{v}\right|=m$

Within Example 1, $\left\{\left(a_{1}, a_{2}, 1,1,2\right),\left(a_{3}, a_{4}, 2,2,-1\right)\right\}$ is a "change of judgements with 3 categories", which consists of

- to replace the judgement $\left(a_{1}, a_{2}\right) \in C_{1}$ with the judgement $\left(a_{1}, a_{2}\right)$ $\in C_{3}$ (augmentation of 2 categories)

- to replace the judgement $\left(a_{3}, a_{4}\right) \in C_{2}$ with the judgement $\left(a_{3}, a_{4}\right)$ $\in C_{1}$ (reduction of 1 category)

Notation: the set of "judgement changes with $m$ categories" which renders the judgements consistent will be denoted by $S u g g_{m}$.

Within Example 1, 
- $\left\{\left(a_{1}, a_{2}, 1,1,2\right),\left(a_{3}, a_{4}, 2,2,-1\right)\right\} \in$ Sugg $_{3}$

- $\left\{\left(a_{1}, a_{3}, 4,4,-1\right)\right\},\left\{\left(a_{3}, a_{4}, 2,2,-1\right)\right\},\left\{\left(a_{1}, a_{2}, 1,1,1\right)\right\}$ and $\left\{\left(a_{2}\right.\right.$, $\left.\left.a_{4}, 3,3,1\right)\right\} \in \operatorname{Sugg}_{1}$,

these are the 4 changes suggested in Section 7.3.

Once the PreSugg group is determined, the third step is to:

- determine the "minimum number of changes" (some possibly successive) necessary to render the judgements consistent;

- determine all of the combinations of such "minimal" changes.

More rigorously, this means

- find $m_{0}=\min \left\{m \in \mathbb{N}^{*} \mid S u g g_{m} \neq \emptyset\right\}$

- clarify $S u g g_{m}$

In Example 1, we have already seen that $m_{0}=1$ ( since $S u g g_{1} \neq \emptyset$ ).

We will proceed as follows for all cases of inconsistency (see Figure $1.3)$.

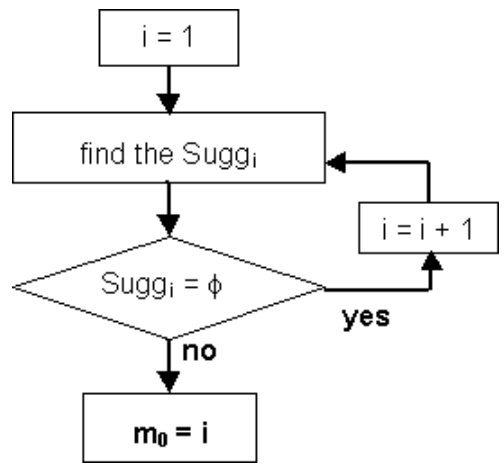

Figure 1.3. Procedure for all cases of inconsistency.

At each step $i$,

- the set of all "judgement changes of $i$ categories", built on the basis of element PreSugg are considered;

- for each of the elements in this group:

- carry out the modifications included in the selected item;

- test the consistency of the new matrix of judgements; if it is consistent, store the element in $\mathrm{Sugg}_{i}$; 
- restore the matrix to the initial judgements.

It is worth mentioning that we consider the possibility of changing a judgement by several categories.

This algorithm is always convergent since one can always give consistent judgements in a finite number of changes.

We emphasize that in practice, the cases of inconsistency that require more than 2 "changes of 1 category" are almost non-existent. The main reason being that any change in judgement that generates an inconsistency is immediately announced to $J$, who must then confirm or cancel his or her judgement.

This procedure allows one to avoid

- coarse errors of distraction (by cancelling the judgement);

- the "accumulation" of inconsistencies since, if $J$ confirms his or her judgement, suggestions of changes that will eliminate the inconsistency are made.

\section{5. $\quad$ Example 2}

Suppose that $X=\left\{a_{1}, a_{2}, a_{3}, a_{4}\right\}$ and that $J$ has formulated the following consistent judgements:

- $P=\left\{\left(a_{1}, a_{2}\right),\left(a_{1}, a_{3}\right),\left(a_{2}, a_{3}\right),\left(a_{3}, a_{4}\right)\right\}$

- $\left(a_{1}, a_{2}\right) \in C_{1},\left(a_{1}, a_{3}\right) \in C_{4},\left(a_{2}, a_{3}\right) \in C_{2},\left(a_{3}, a_{4}\right) \in C_{3}$

Suppose that $J$ adds that $a_{2} \mathrm{~Pa}_{4}$ and that $\left(a_{2}, a_{4}\right) \in C_{3}$ : M-MACBETH informs $J$ that his or her judgements are "inconsistent".

If $J$ confirms the judgement $\left(a_{2}, a_{4}\right) \in C_{3}$, M-MACBETH will display the message: "Inconsistent judgements: MACBETH has found 6 ways to render the judgements matrix consistent with 2 category changes."

This time, it will be necessary to make at least 2 "changes of 1 category" to render the judgements consistent; there are 6 distinct combinations of such changes. Each of these 6 suggestions is presented graphically (see Figure 1.4) within the table of judgements, accompanied by SEI which, moreover, shows why the suggestions made eliminate this incompatibility: Figure 1.4 presents the first of six suggestions. 


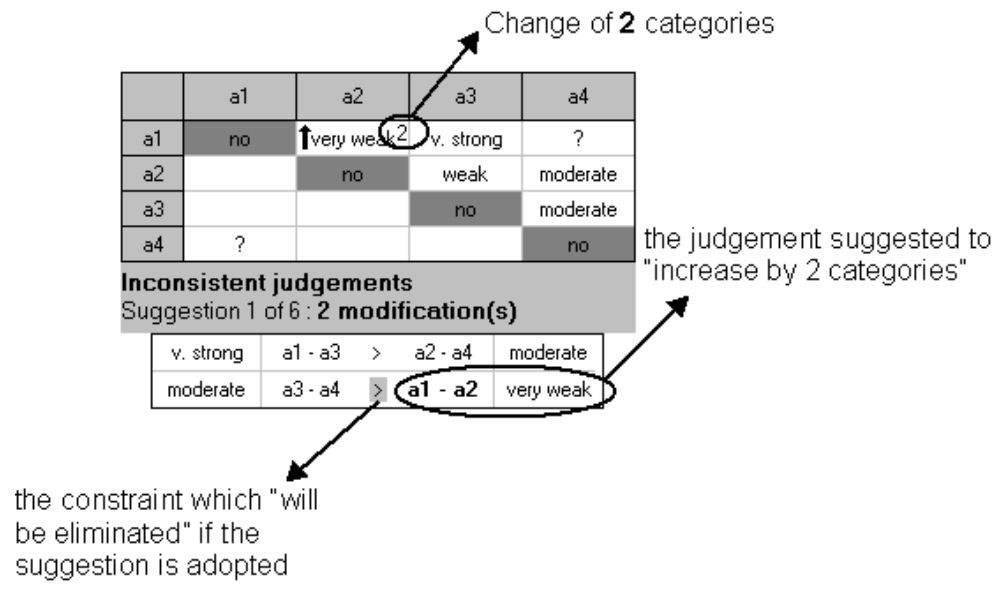

Figure 1.4. Suggestion of change to resolve inconsistency.

\section{The MACBETH Scale}

\subsection{Definition of the MACBETH Scale}

Suppose that $S c_{1+2} \neq \phi$ and $a_{1}(P \cup I) a_{2} \ldots a_{n-1}(P \cup I) a_{n}$. The linear program LP-MACBETH with variables $x_{1}, \ldots, x_{n}, \sigma_{1}, \ldots, \sigma_{Q}$ is therefore feasible:

$\min x_{1}$

subject to

$$
\begin{array}{ll}
x_{p}-x_{r}=0 & \forall\left(a_{p}, a_{r}\right) \in I \text { with } p<r \\
\sigma_{i}+\frac{1}{2} \leq x_{p}-x_{r} & \forall i, j \in N_{1, Q} \text { with } i \leq j, \forall\left(a_{p}, a_{r}\right) \in C_{i j} \\
x_{p}-x_{r} \leq \sigma_{j+1}-\frac{1}{2} & \forall i, j \in N_{1, Q-1} \text { with } i \leq j, \forall\left(a_{p}, a_{r}\right) \in C_{i j} \\
\sigma_{1}=\frac{1}{2} & \\
\sigma_{i-1}+1 \leq \sigma_{i} & \forall i \in N_{2, Q} \\
x_{i} \geq 0 & \forall i \in N_{1, n} \\
\sigma_{i} \geq 0 & \forall i \in N_{1, Q}
\end{array}
$$

Definition 12 Any function EchMac $: X \rightarrow \mathbb{R}$ such that $\forall i \in \mathbb{N}_{1, n}$, $\operatorname{EchMac}\left(a_{i}\right)=x_{i}^{*}-$ where $\left(x_{1}^{*}, \ldots, x_{n}^{*}\right)$ is an optimal solution of LPMACBETH - is called a basic MACBETH scale.

Definition $13 \forall a \in \mathbb{R}_{+}^{*}, \forall b \in \mathbb{R}$ with $(a, b) \neq(1,0), a \cdot$ EchMac $+b$ is a transformed MACBETH scale. 


\subsection{Discussing the Uniqueness of the Basic MACBETH Scale}

Nothing guarantees that a LP-MACBETH optimal solution is unique. For example, consider the matrix of judgements and the basic MACBETH scale shown is Figure 1.5.

\begin{tabular}{|c|c|c|c|c|c|c|}
\hline & a1 & a2 & a3 & a4 & a5 & a6 \\
\hline a1 & no & very weak & weak & moderate & moderate & strong \\
\hline a2 & & no & very weak & moderate & moderate & moderate \\
\hline a3 & & & no & weak & moderate & moderate \\
\hline a4 & & & & no & very weak & very weak \\
\hline a5 & & & & & no & very weak \\
\hline a6 & & & & & & no \\
\hline
\end{tabular}

\begin{tabular}{|r|r|}
\hline a1 & $\begin{array}{c}\text { Macbeth } \\
\text { basic }\end{array}$ \\
\hline a2 & $\mathbf{8 . 0 0}$ \\
\hline a3 & 5.50 \\
\hline a4 & 2.00 \\
\hline a5 & 2.00 \\
\hline a6 & 1.00 \\
\hline
\end{tabular}

Figure 1.5. Matrix of judgements and basic MACBETH scale.

One can verify that, $\forall x \in[6,7],(8, x, 5,2,1,0)$ is still an optimal solution of LP-MACBETH. Thus, a basic MACBETH scale is not necessarily unique. As long as the MACBETH scale is interpreted as a technical aid whose purpose is to provide the foundation for a discussion with $J$, this does not constitute a true problem. However, we have observed that in practice decision makers often adopt the MACBETH scale as the final scale. It is, therefore, convenient to guarantee the uniqueness of the MACBETH scale. This is obtained technically, as follows (where $S_{\text {mac }}$ is the group of the constraints of LP-MACBETH):

$$
\begin{aligned}
\text { Step 1) solution of LP-MACBETH } & \\
& \rightarrow \text { optimal solution } x_{1}, x_{2}, \ldots, x_{n} \\
& \rightarrow \mu\left(a_{1}\right)=x_{1}, \mu\left(a_{n}\right)=x_{n}=0 \text { (remark: } \mu\left(a_{1}\right) \text { is unique) }
\end{aligned}
$$

Step 2) for $i=2$ to $n-1$

to solve $\max x_{i}$ under $\left\{\begin{array}{l}S_{\text {mac }} \\ x_{1}=\mu\left(a_{1}\right), \ldots, x_{i-1}=\mu\left(a_{i-1}\right)\end{array}\right.$

$\rightarrow$ optimal solution $x_{1}, x_{2}, \ldots, x_{n}$

$\rightarrow x \max =x_{i}$

to solve $\min x_{i}$ under $\left\{\begin{array}{l}S_{\text {mac }} \\ x_{1}=\mu\left(a_{1}\right), \ldots, x_{i-1}=\mu\left(a_{i-1}\right)\end{array}\right.$

$\rightarrow$ optimal solution $x_{1}, x_{2}, \ldots, x_{n}$

$\rightarrow$ xmin $=x_{i}$

$$
\mu\left(a_{i}\right)=\frac{x \min +x \max }{2}
$$

Thus, 
- to calculate $\mu\left(a_{2}\right)$, the variable $x_{1}$ is "fixed" to the value $\mu\left(a_{1}\right)$, the minimum and maximum values of $x_{2}$ are calculated and the average of the two results is taken as the value of $\mu\left(a_{2}\right)$;

- to calculate $\mu\left(a_{3}\right)$, the variable $x_{1}$ is "fixed" to the value of $\mu\left(a_{1}\right)$, the variable $x_{2}$ is "fixed" to the value of $\mu\left(a_{2}\right)$, the minimum and maximum values of $x_{3}$ are calculated and the average of the two values is taken as the value of $\mu\left(a_{3}\right)$;

- etc.

This method guarantees that $\mu\left(a_{1}\right), \mu\left(a_{2}\right), \ldots \mu\left(a_{n}\right)$ are unique for a given preferential information $\left\{P, I, ?=\phi, P^{e}\right\}$. It permits us to speak of "the" basic MACBETH scale, instead of "one" MACBETH scale.

\subsection{Presentation of the MACBETH Scale}

The MACBETH scale that corresponds to $\left\{P, I, ?=\phi, P^{e}\right\}$ consistent information is represented in two ways in M-MACBETH: a table and a "thermometer". In the example in Figure 1.6, the transformed MACBETH scale represented in the thermometer was obtained by imposing the values of the elements $d$ and $c$ as 100 and 0 respectively.

\begin{tabular}{|c|c|c|c|c|c|}
\hline & $d$ & $a$ & $e$ & $b$ & $c$ \\
\hline$d$ & no & weak & strong & strong & extreme \\
\hline a & & no & moderate & moderate & v. strong \\
\hline e & & & no & very weak & weak \\
\hline b & & & & no & weak \\
\hline c & & & & & no \\
\hline
\end{tabular}

$\mathrm{d}$ and $\mathrm{c}$ fixed to 100 and 0
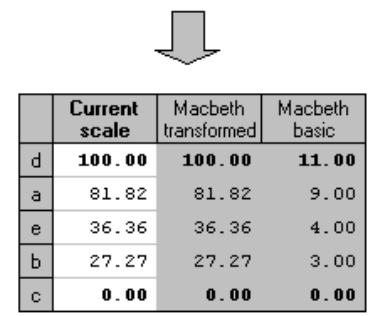

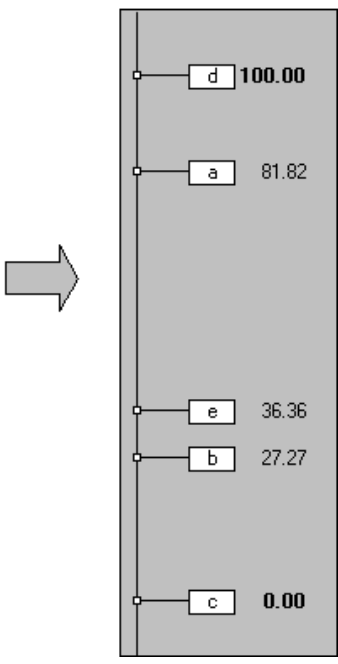

Figure 1.6. Representations of the MACBETH scale.

Even though the values attributed to $c$ and $d$ are fixed, in general an infinite number of scales that satisfy Conditions 1 and 2 exist. It is, thus, necessary to allow $J$ to, should he or she want to, modify the values suggested. This is the subject of the next section. 


\section{Discussion About a Scale}

Suppose that, in the example in Figure 1.6, $J$ considers that the element $a$ is badly positioned when compared to elements $c$ and $d$ and therefore $J$ wants to redefine the value of $a$. It is then interesting to show $J$ the limits within which the value of $a$ can vary without violating the preferential information provided by $J$. Let us suppose in this section that we have a type $1+2$ information about $X$ which is consistent and that $?=\phi$.

Let $\mu_{0}$ be a particular scale of $S c_{1+2}, L$ and $H$ be two fixed elements of $X$ with $H P L$ ( $H$ more attractive than $L)$ and $a$ be an element of $X$ (not indifferent to $L$ and not indifferent to $H$ ) that $J$ would like to have repositioned.

Let

- $S c_{\left(\mu_{0}, H, L\right)}=\left\{\mu \in S c_{1+2} \mid \mu(H)=\mu_{0}(H)\right.$ and $\left.\mu(L)=\mu_{0}(L)\right\}$ (scales for which values associated with $H$ and $L$ have been fixed)

- $S c_{\left(\mu_{0}, \hat{a}\right)}=\left\{\mu \in S c_{1+2} \mid \forall y \in X\right.$ with $y$ not indifferent to $a$ : $\left.\mu(y)=\mu_{0}(y)\right\}$ (scales for which the values of all of the elements of $X$ except $a$ and its eventual equals have been fixed).

We call free interval associated to interval $a$ :

$$
\inf _{\mu \in S c_{\left(\mu_{0}, H, L\right)}} \mu(a), \sup _{\mu \in S c_{\left(\mu_{0}, H, L\right)}} \mu(a)[
$$

We call dependent interval associated to interval $a$ :

$$
\inf _{\mu \in S c_{\left(\mu_{0}, \hat{a}\right)}} \mu(a), \sup _{\mu \in S c_{\left(\mu_{0}, \hat{a}\right)}} \mu(a)[
$$

In the example in Figure 1.6, if one selects $a$, two intervals are presented to $J$ (see Figure 1.7) which should be interpreted as follows:

$$
\begin{gathered}
\forall \mu \in S c_{1+2},[\mu(c)=0, \mu(d)=100] \Rightarrow 66.69 \leq \mu(a) \leq 99.98 . \\
\forall \mu \in S c_{1+2},[\mu(c)=0, \mu(d)=100, \mu(e)=36.36, \mu(b)=27.27] \\
\Rightarrow 72.74 \leq \mu(a) \leq 90.9 .
\end{gathered}
$$

The closed intervals (in the example [66.69,99.98] and [72.74,90.9]) that have been chosen to present to $J$ are not the precise free and dependent intervals associated to $a$ (which, by definition, are open); however, by taking a precision of 0.01 into account, they can be regarded as the "greatest" closed intervals included in the free and dependent intervals. 
M-MACBETH permits the movement of element $a$ with the mouse but, obviously, only inside of the dependent interval associated to $a$.

If $J$ wants to give element $a$ a value that is outside of the dependent interval (but still inside the free interval), the software points out that the values of the other elements must be modified. If $J$ confirms the new value of $a$, a new MACBETH scale is calculated, taking into account the additional constraint that fix the new value of $a$.

The ("closed") free interval is calculated by integer linear programming. The ("closed") dependent interval could be also calculated in the same manner. However, M-MACBETH computes it by "direct" calculation formulas which make the determination of these intervals extremely fast - for details, see [46].

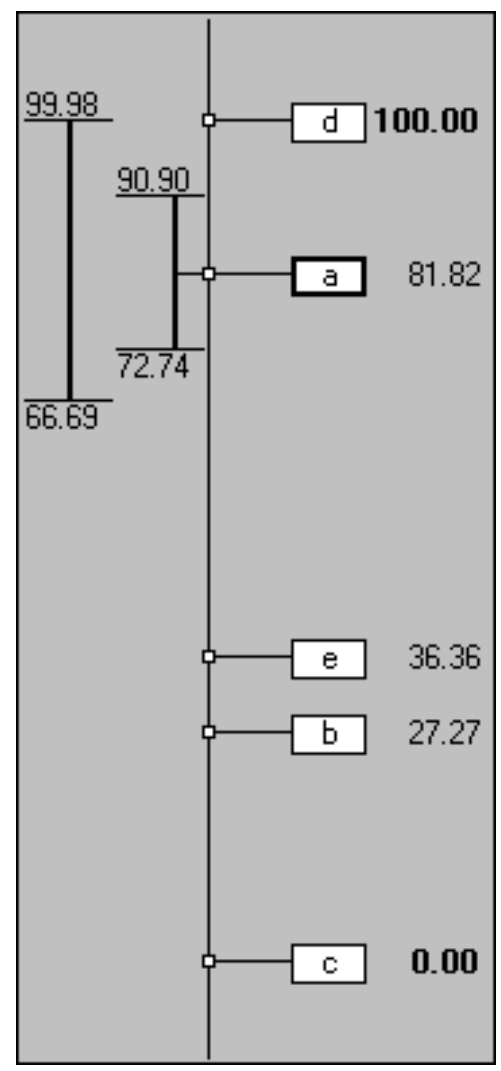

Figure 1.7. "Greatest" closed intervals included in the free and dependent intervals. 


\section{MACBETH and MCDA}

The MACBETH approach and the M-MACBETH software have been used to derive preference scales or value functions and scaling constants in many public and private applications of multicriteria additive value analysis, some of them reported in the literature:

- Evaluation of bids in international public calls for tenders and contractors' choice - see [3, 5, 10, 11, 12, 19, 20, 21, 33] and [58].

- Management of European structural programs - see [37, 42] and [43].

- Public policy analysis, prioritization of projects, resources allocation and conflict management - see [4, 22, 23, 24, 25, 26, 33] and [60].

- Suppliers performance evaluation - see [7] and [57].

- Credit scoring - see [8].

- Strategic town planning - see [14] and [15].

- Environmental management and evaluation of flood control measures - see [1,6] and [17].

- Portfolio management - see [27].

- Airport management - see [39].

- Human resources evaluation and management - see [50, 47, 48] and [54].

- Total Quality Management - see [11].

- Firms' competitiveness, resource allocation and risk management - see [13] and [49].

- Location of military facilities - see [28].

- Applications in the telecommunications sector - see [18] and [44].

\section{Acknowledgment}

The authors thank Manuel Pedro Chagas and two anonymous referees 


\section{References}

[1] P. Antão da Silva, C.A. Bana e Costa, and F.N. Correia. Avaliação multicritério das incidências ambientais de medidas de controlo de cheias: Aplicação à bacia hidrográfica da Ribeira do Livramento. In Trabalhos Técnicos do $1^{\circ}$ Congresso sobre Aproveitamento e Gestão de Recursos Hídricos em Países de Idioma Português, pages 210-217, Rio de Janeiro, 2000. Associação Brasileira de Engenharia Sanitária e Ambiental. CD-ROM edition.

[2] C.A Bana e Costa. Structuration, Construction et Exploitation d'un Modèle Multicritère d'Aide à la Décision. PhD thesis, Technical University of Lisbon, Lisbon, 1992.

[3] C.A. Bana e Costa. O modelo de apoio à avaliação de propostas nos concursos do Metro do Porto. FER XXI, XVIII:111-115, 1999.

[4] C.A. Bana e Costa. The use of multicriteria decision analysis to support the search for less conflicting policy options in a multi-actor context: Case-study. Journal of Multi-Criteria Decision Analysis, 10(2):111-125, 2001.

[5] C.A. Bana e Costa. Issues in facilitating bid evaluation in public call for tenders. In F. Khosrowshahi, editor, Proceedings of the 3rd International Conference on Decision Making in Urban and Civil Engineering, pages 703-709, London, 2002. SOAS. CD-ROM edition.

[6] C.A. Bana e Costa, P. Antão da Silva, and F.N. Correia. Multicriteria evaluation of flood control measures: The case of Ribeira do Livramento. Water Resources Management, to appear, 2004.

[7] C.A. Bana e Costa, G. Appa, M.P. Chagas, F.C. Ferreira, J.O. Soares, R.C. Souza, and A. Zanini. A methodology to estimate the relative operational performance of electricity distributors. Technical report, PUC-Rio, Pontifícia Universidade Católica do Rio de Janeiro, 2002.

[8] C.A. Bana e Costa, L. Barroso, and J.O. Soares. Qualitative modelling of credit scoring: A case study in banking. Journal of European Research Studies, V(12):37-51, 2002.

[9] C.A. Bana e Costa and M.P. Chagas. A career choice problem: An example of how to use MACBETH to build a quantitative value model based on qualitative value judgements. European Journal of Operational Research, 153:323-331, 2004.

[10] C.A. Bana e Costa and E.C. Corrêa. Framing public calls for tenders through a multicriteria approach. In D.K. Despotis and C. Zopounidis, editors, Proceedings 
of the 5th International Conference of the Decision Sciences Institute, volume II, pages 1353-1355, Athens, 1999. Athens University of Business and Economics.

[11] C.A. Bana e Costa and E.C. Corrêa. Construction of a total quality index using a multicriteria approach: The case of Lisbon Gas Company. Research paper 10/2000, CEG-IST, Technical University of Lisbon, 2000.

[12] C.A. Bana e Costa, E.C. Corrêa, J.M. De Corte, and J.C. Vansnick. Facilitating bid evaluation in public call for tenders: A socio-technical approach. OMEGA: The International Journal of Management Science, 30(3):227-242, 2002.

[13] C.A. Bana e Costa, E.C. Corrêa, L. Ensslin, and J.C. Vansnick. Decision support systems in action: Integrated application in a multicriteria decision aid process. European Journal of Operational Research, 113(2):315-335, 1999.

[14] C.A. Bana e Costa, M.L. Costa-Lobo, and I.A. Ramos. Contributo da metodologia multicritério na elaboração do Plano Estratégico de Barcelos. Sociedade e Território, 24:102-115, 1997.

[15] C.A. Bana e Costa, M.L. da Costa-Lobo, I.A. Ramos, and J.C. Vansnick. Multicriteria approach for strategic town planning: The case of Barcelos. In D. Bouyssou, E. Jacquet-Lagrèze, P. Perny, R. Sĺowiński, D. Vanderpooten, and Ph. Vincke, editors, Aiding Decisions with Multiple Criteria. Essays in Honor of Bernard Roy, pages 429-456. Kluwer Academic Publishers, Boston, 2002.

[16] C.A. Bana e Costa, J.M. De Corte, and J.C. Vansnick. MACBETH. Working paper 03.56, London School of Economics, 2003.

[17] C.A. Bana e Costa, L. Ensslin, and E. Holz. Avaliação ambiental em situação de conflito de interesses - Um estudo de caso. In IX SILUBESA, Simpósio LusoBrasileiro de Engenharia Sanitária e Ambiental, pages 1914-1923. Associação Brasileira de Engenharia Sanitária e Ambiental and Associação Portuguesa de Recursos Hídricos, Porto Seguro (BA), 2000. CD-ROM edition.

[18] C.A. Bana e Costa, L. Ensslin, and I.J. Zanella. A real-world MCDA application in cellular telephony systems. In T.J. Stewart and R.C. van den Honert, editors, Trends in Multicriteria Decision Making, volume 465 of Lecture Notes in Economics and Mathematical Systems, pages 412-423. Springer-Verlag, Berlin, 1998.

[19] C.A. Bana e Costa and J.A. Ferreira. Concursos de obras públicas: Metodologia de avaliação de propostas. Aplicação a uma grande empreitada de infraestruturas de transportes. In Actas do Congresso 94, Engenharia Portuguesa na Viragem do Século, pages 47-w/9, Lisbon, 1994. Ordem dos Engenheiros.

[20] C.A. Bana e Costa, J.A. Ferreira, and E.C. Corrêa. Metodologia multicritério de apoio à avaliação de propostas em concursos públicos. In C.H. Antunes and L.V. Tavares, editors, Casos de Aplicação da Investigação Operacional, pages 336-363. McGraw-Hill Portugal, Lisbon, 2000.

[21] C.A. Bana e Costa, J.A. Ferreira, and J.C. Vansnick. Avaliação multicritério de propostas: O caso de uma nova linha do Metropolitano de Lisboa. Revista de Transporte e Tecnologia, VII(14):31-65, 1995. 
[22] C.A. Bana e Costa and R.C. Oliveira. Assigning priorities for maintenance, repair and refurbishment in managing a municipal housing stock. European Journal of Operational Research, 138(2):380-391, 2002.

[23] C.A. Bana e Costa, R.C. Oliveira, and M.L. Alvarez. Concepção de um sistema multicritério de definição de prioridades de intervenção/conservação do património habitacional da Câmara Municipal de Lisboa. In Comunicações ao $2^{o}$ Encontro sobre Conservação e Reabilitação de Edifícios, volume II, pages 925-934. LNEC, Laboratório Nacional de Engenharia Civil, Lisbon, 1994.

[24] C.A. Bana e Costa, R.C. Oliveira, and M.L. Alvarez. SMAI: Sistema multicritério de avaliação de intervenções num parque habitacional municipal. In A.A. Bezelga and A.B. Leitão, editors, A Avaliação do Imobiliário, pages 109122. Associação Portuguesa dos Avaliadores de Engenharia, Lisbon, 1997.

[25] C.A. Bana e Costa and F.N. Silva. Concepção de uma 'boa' alternativa de ligação ferroviária ao porto de Lisboa: Uma aplicação da metodologia multicritério de apoio à decisão e à negociação. Investigação Operacional, 14(2):115-131, 1994.

[26] C.A. Bana e Costa, F.N. Silva, and J.C. Vansnick. Conflict dissolution in the public sector: A case-study. European Journal of Operational Research, 130(2):388-401, 2001.

[27] C.A. Bana e Costa and J.O. Soares. A multicriteria model for portfolio management. European Journal of Finance, 10(3):to appear, 2004.

[28] C.A. Bana e Costa and J.F. Thomaz. Locating centres of information and recruitment of volunteers for the Portuguese armed forces: A decision-analysis case-study. In Proceedings of the 42nd Annual Conference of the International Military Testing Association, pages 173-180. International Military Testing Association, Edinburgh, 2000,. CD-ROM edition.

[29] C.A. Bana e Costa and J.C. Vansnick. Sur la quantification des jugements de valeur: L'approche MACBETH. Cahiers du LAMSADE, 117, Université ParisDauphine, Paris, 1993.

[30] C.A. Bana e Costa and J.C. Vansnick. MACBETH - An interactive path towards the construction of cardinal value functions. International Transactions in Operational Research, 1(4):489-500, 1994.

[31] C.A. Bana e Costa and J.C. Vansnick. General overview of the MACBETH approach. In P.M. Pardalos, Y. Siskos, and C. Zopounidis, editors, Advances in Multicriteria Analysis, pages 93-100. Kluwer Academic Publishers, Dordrecht, 1995.

[32] C.A. Bana e Costa and J.C. Vansnick. Uma nova abordagem ao problema de construção de uma função de valor cardinal: MACBETH. Investigação Operacional, 15(1):15-35, 1995.

[33] C.A. Bana e Costa and J.C. Vansnick. Applications of the MACBETH approach in the framework of an additive aggregation model. Journal of Multi-Criteria Decision Analysis, 6(2):107-114, 1997.

[34] C.A. Bana e Costa and J.C. Vansnick. L'approche MACBETH : Note technique de presentation. Research paper 779, CESUR, Technical University of Lisbon, 1997. 
[35] C.A. Bana e Costa and J.C. Vansnick. The MACBETH approach: Basic ideas. In Proceedings of the International Conference on Methods and Applications of Multicriteria Decision Making, pages 86-88. FUCAM, Facultés Universitaires Catholiques de Mons, 1997.

[36] C.A. Bana e Costa and J.C. Vansnick. A theoretical framework for measuring attractiveness by a categorical based evaluation technique (MACBETH). In J. Clímaco, editor, Multicriteria Analysis, pages 15-24. Springer-Verlag, Berlin, 1997.

[37] C.A. Bana e Costa and J.C. Vansnick. The MACBETH approach: Basic ideas, software and an application. In N. Meskens and M. Roubens, editors, Advances in Decision Analysis, pages 131-157. Kluwer Academic Publishers, Dordrecht, 1999.

[38] C.A. Bana e Costa and J.C. Vansnick. Cardinal value measurement with MACBETH. In S.H. Zanakis, G. Doukidis, and C. Zopounidis, editors, Decision Making: Recent Developments and Worldwide Applications, pages 317-329. Kluwer Academic Publishers, Dordrecht, 2000.

[39] C.A. Bana e Costa and A.C. Vitorino. Construção multicritério da 'matriz de custos' de um modelo de afectação para gestão de stands de aeronaves. Investigação Operacional, 17(2):179-199, 1997.

[40] V. Belton. A Comparative Study of Methods for Multiple Criteria Decision Aiding. PhD thesis, University of Cambridge, Cambridge, U.K., 1986.

[41] V. Belton and T.J. Stewart. Multiple Criteria Decision Analysis: An Integrated Approach. Kluwer Academic Publishers, Boston, 2002.

[42] C3E, editor. Applying the Multi-criteria Method to the Evaluation of Structural Programmes, volume 4 of MEANS Handbook. European Commission, DG XVI/02, Brussels, 1995.

[43] C3E, editor. Evaluation Pilote Multicritère du Hainaut. Rapport d'Expérience. European Commission, DG XVI/02, Brussels, 1995.

[44] F.J.P. Cardoso, L.F.A.M. Gomes, and M. Sanglard Júnior. Administração das operações de telecomunicação: Uma análise de decisão. Revista Portuguesa e Brasileira de Gestão, 2(2):91-103, 2003.

[45] Catalyze Ltd. HIVIEW3 Starter Guide. Catalyze Ltd, London, 2003.

[46] J.M. De Corte. Un Logiciel d'Exploitation d'Informations Préférentielles pour l'Aide à la Décision. Bases Mathématiques et Algorithmiques. PhD thesis, University of Mons-Hainaut, Mons, 2002.

[47] L. Ensslin, A. Dutra, and S. Ensslin. MCDA: A constructivist approach to the management of human resources at a governmental agency. International Transactions in Operational Research, 7(1):79-100, 2000.

[48] L. Ensslin and S. Ensslin. Elaboração de um modelo construtivista para identificação de oportunidades de aperfeiçoamento de docentes do EPS-UFSC. Revista Produto E Produção, 2(3):143-149, 1998.

[49] L. Ensslin, G.N. Montibeller, and M.V.A Lima. Constructing and implementing a DSS to help evaluate perceived risk of accounts receivable. In Y.Y. Haimes 
and R.E. Steuer, editors, Research and Practice in Multiple Criteria Decision Making, volume 487 of Lecture Notes in Economics and Mathematical Systems, pages 245-259. Springer-Verlag, Berlin, 2000.

[50] L. Ensslin, G.N. Montibeller, and S. Noronha. Apoio à Decisão: Metodologias para Estruturação de Problemas e Avaliação Multicritério de Alternativas. Editora Insular, Florianópolis (SC), 2001.

[51] P.H. Farquhar and L.R. Keller. Preference intensity measurement. In P.C. Fishburn and I.H. LaValle, editors, Choice under Uncertainty, volume 19 of Annals of Operations Research, pages 205-217. 1989.

[52] A.N.S. Freeling. Belief and Decision Aiding. PhD thesis, University of Cambridge, U.K., 1983.

[53] S. French. Decision Theory: An Introduction to the Mathematics of Rationality. Ellis Horwood Limited, Chichester, 1988.

[54] M.A.L Leitão, J.F. Thomaz, F.V. Freire, and C.A. Bana e Costa. Using decision conferencing and process consultation to facilitate the structuring of a performance appraisal model in the Portuguese army. Research paper 5/2002, CEG-IST, Technical University of Lisbon, 2002.

[55] O.L. Mangasarian. Nonlinear Programming. McGraw-Hill, New York, 1969.

[56] C. Mousset and J.C. Vansnick. About the representation of a precardinal information. Technical report, Université de Mons-Hainaut, 2002.

[57] R.C. Oliveira and J.C. Lourenço. A multicriteria model for assigning new orders to service suppliers. European Journal of Operational Research, 139(2):390-399, 2002.

[58] J.L. Porto. Analyse multicritère dans le cadre des appels d'offres pour la construction de travaux publics et privés : Le cas du Métro de Porto au Portugal. Newsletter of the European Working Group 'Multiple Criteria Decision Aiding', Serie II (15):1-2, 1999.

[59] T.L. Saaty. The Analytic Hierarchy Process. McGraw-Hill, New York, 1980.

[60] J.S.V. Silva and C.A. Bana e Costa. Especificação de uma ferramenta de apoio à decisão para gestão pública em regiões semi-áridas. Research paper 23/2001, CEG-IST, Technical University of Lisbon, 2001.

[61] D. von Winterfeldt and W. Edwards. Decision Analysis and Behavioral Research. Cambridge University Press, Cambridge, 1986.

[62] S.R. Watson and D.M. Buede. Decision Synthesis: The Principles and Practice of Decision Analysis. Cambridge University Press, Cambridge, 1987. 